\title{
Research on the Design of Miniature Pile Foundation for Transmission Line
}

\author{
Xinmin $\mathrm{Yu}^{1}$, Xianri Wang ${ }^{2}$ \\ ${ }^{1}$ Structural engineering, State GRID Fujian Economic Research Institute, FuZhou, FuJian, 350000, China \\ ${ }^{2}$ Power System and Automation, State GRID Fujian Economic Research Institute, FuZhou, FuJian, 350000, China
}

\begin{abstract}
Micro-pile is a kind of small diameter bored piles, also known as root pile, pile diameter is generally $150-400 \mathrm{~mm}$, length-diameter ratio is generally greater than 30 , and pile length is usually not more than 30m. Compared with ordinary pile, micro-pile has the advantages of fast construction speed, small working surface, high bearing capacity and small settlement.
\end{abstract}

\section{Introduction}

For the transmission line tower foundation with uneven settlement, reinforced concrete slab foundation and cast-in-place pile foundation are usually adopted according to the geological conditions. The use of miniature pile foundation can effectively reduce the construction difficulty and engineering amount, reduce the damage to the natural environment, reduce the project cost, in line with the state grid corporation of China "two types and three new" requirements ${ }^{[1]}$.

\section{Economic comparison between excavation pile foundation and miniature pile foundation}

The basic forces of the state grid universal tower type 2e3-sjc1 are compared as shown in Table 1:

Table 1 Indexes of foundation concrete and steel consumption

\begin{tabular}{|c|c|c|c|c|c|c|}
\hline Tower type & Basic type & $\begin{array}{c}\text { Buried depth } \\
(\mathrm{m})\end{array}$ & $\begin{array}{c}\text { The pile } \\
\text { diameter } \\
(\mathrm{m})\end{array}$ & $\begin{array}{c}\text { concrete } \\
(\mathrm{m} 3)\end{array}$ & $\begin{array}{c}\text { Based on the } \\
\text { steel } \\
(\mathrm{kg})\end{array}$ & Base material \\
\hline \multirow{2}{*}{2 e3y - SJC1 } & Dig-hole pile & 12 & 1.0 & 38.0 & 3255.0 & $100 \%$ \\
\cline { 2 - 7 } & Miniature pile & 8 & $0.20 \times 4$ & 40.4 & 1835.8 & $90 \%$ \\
\hline
\end{tabular}

It can be seen from the comparison of the above table that the comprehensive cost of choosing miniature pile foundation is lower than that of digging hole pile foundation.

\section{Comparison of mechanized construction of bored pile foundation and miniature pile foundation}

Table 2 Construction comparison of different foundation types

\begin{tabular}{|c|l|l|}
\hline Basic type & \multicolumn{1}{|c|}{ Construction conditions } & \multicolumn{1}{|c|}{ Basic characteristics of } \\
\hline \multirow{3}{*}{ Dig-hole pile } & $\begin{array}{l}\text { Digging hole pile can realize mechanized } \\
\text { construction with high rate of pile } \\
\text { formation, but it has higher requirements on } \\
\text { construction site and needs larger } \\
\text { construction space }{ }^{[2]}\end{array}$ & $\begin{array}{l}\text { The bearing capacity of the miniature pile } \\
\text { foundation is relatively low, and the pile } \\
\text { diameter is greater than 600mm. Once } \\
\text { perfusion molding, high pile rate; For single } \\
\text { pile foundation, each pile is straight pile. }\end{array}$ \\
\hline
\end{tabular}




\begin{tabular}{|c|c|c|}
\hline $\begin{array}{l}\text { Iiniature } \\
\text { pile }\end{array}$ & $\begin{array}{l}\text { With the use of small drilling machine, the } \\
\text { construction speed is fast, but the } \\
\text { construction quality is difficult to } \\
\text { accurately control, and the requirements on } \\
\text { the construction site are low }{ }^{[4]} \text {. The } \\
\text { minimum construction space is only } \\
0.6 \mathrm{~m} \times 2.0 \mathrm{~m} \times 2.5 \mathrm{~m} \text {. }\end{array}$ & $\begin{array}{l}\text { The bearing capacity of bored pile } \\
\text { foundation is relatively high, and the pile } \\
\text { diameter is generally between } 150 \mathrm{~mm} \text { and } \\
400 \mathrm{~mm} \text {. Need to carry out secondary } \\
\text { grouting, construction process is complex; } \\
\text { For group pile foundation, straight pile and } \\
\text { inclined nile can be selected }{ }^{[3]}\end{array}$ \\
\hline
\end{tabular}

\section{Optimization of micro-pile foundation structure}

The optimization of the foundation structure firstly establishes the miniature pile foundation solid model of the tower foundation through the finite element numerical simulation software ANSYS WORKBENCH, and verifies the effectiveness of the design by applying load. The design of the miniature pile is more reasonable through the choice of the cap. Through the comparative analysis of the stress performance of the straight pile and the inclined pile foundation, the paper reasonably arranges the straight pile and the inclined pile of the miniature pile. By changing the pile length parameters. Through the above optimization, the design of miniature pile foundation is more reasonable, the engineering cost is reduced and the reliability of foundation is improved.

\section{Preliminary selection and simulation verification of miniature pile foundation type}

Micro-pile group commonly used in transmission line engineering has four pile caps and nine pile caps foundation, and its plane schematic diagram is shown in Figure 1(a)(b) respectively. According to the previous design experience, the mechanical performance of nine-pile cap foundation with the same pile diameter is obviously better than that of four-pile cap foundation, but the construction technology and engineering cost of nine-pile cap mini-pile foundation are higher than that of four-pile cap mini-pile foundation. According to the design requirements of "two types and three new" of the state grid, improve the design level and prepare for the design of higher grade transmission lines in the future, this chapter chooses to conduct comparative analysis and optimization of four pile cap foundation and nine pile cap foundation.

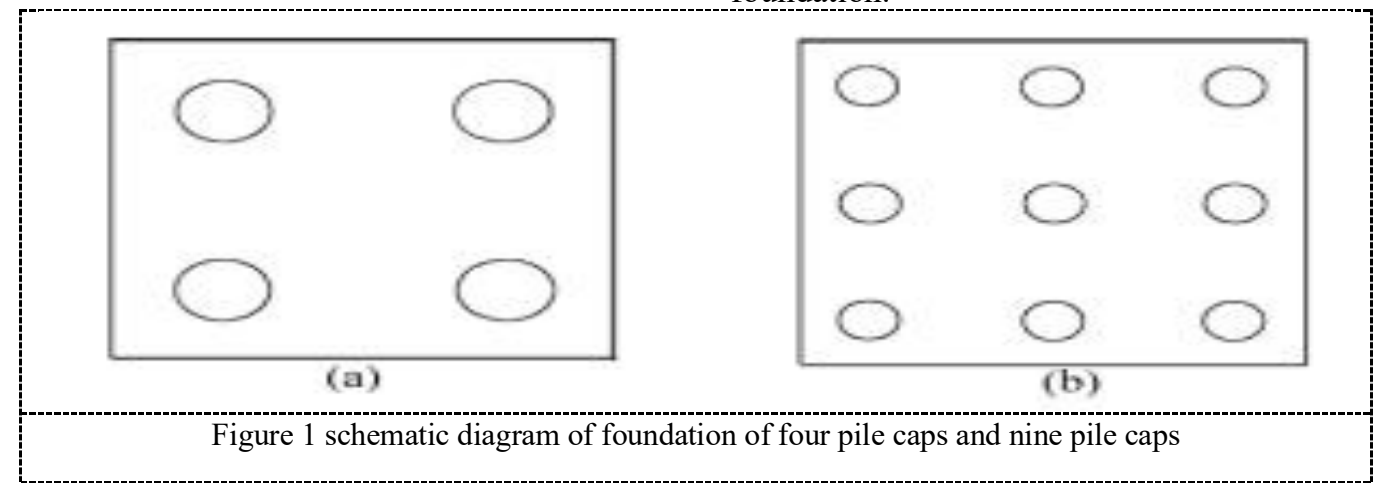

The finite element numerical simulation software ANSYS WORKBENCH was used to establish the solid foundation of the tower foundation, as shown in Figure 2 model of the mini pile nine pile cap and the four pile cap and Figure 3 respectively:

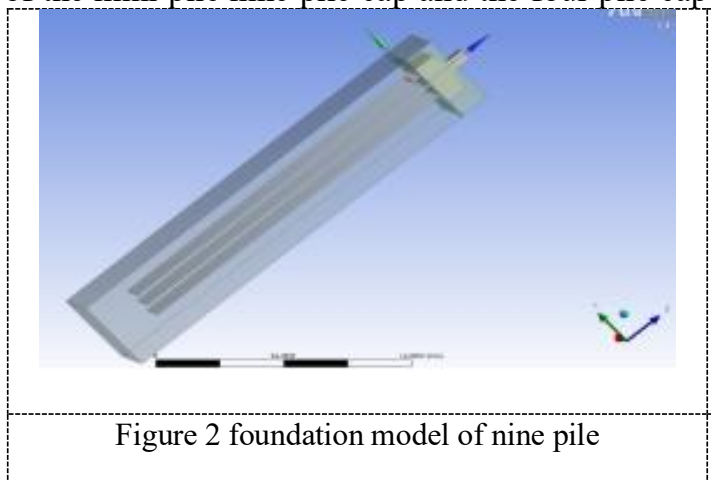

Applying the foundation force of $2 \mathrm{e} 3$-sjc1, the stress and strain distribution cloud diagram of the four pile caps foundation is shown in figure 4-4. The strength of the

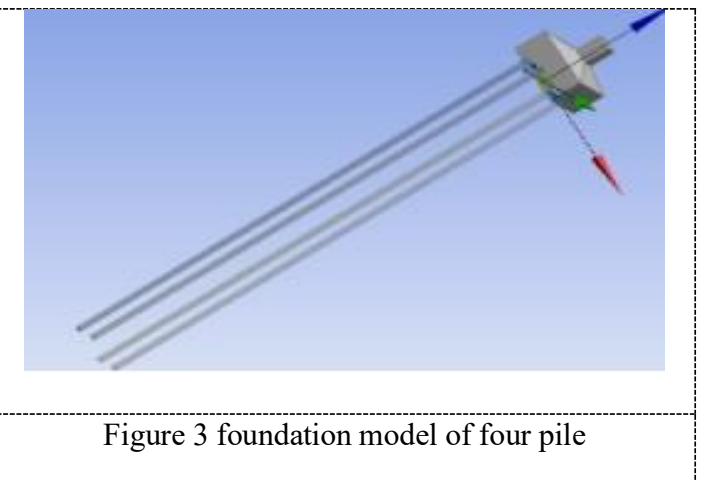

four pile caps straight pile foundation is in line with the design requirements of this project. 


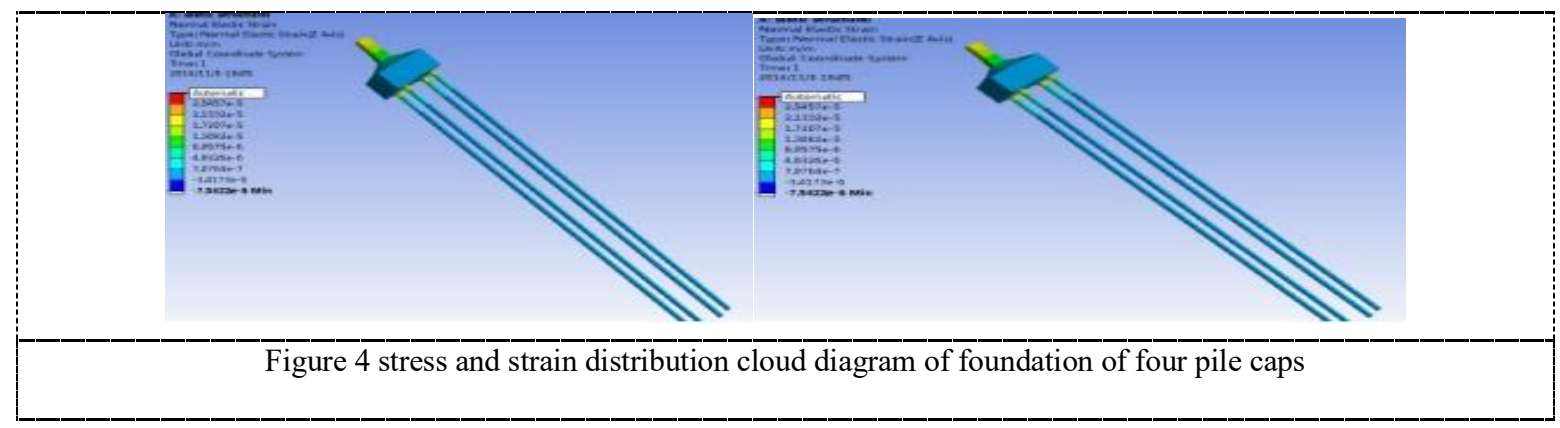

\section{Optimized layout of miniature pile body}

The complexity of micro-pile foundation structure makes the interaction law of cap, pile and soil of micro-pile foundation and the determination of working characteristic parameters become very complicated under the single or combined action of uplift, compression and horizontal overturning load, which finally leads to the

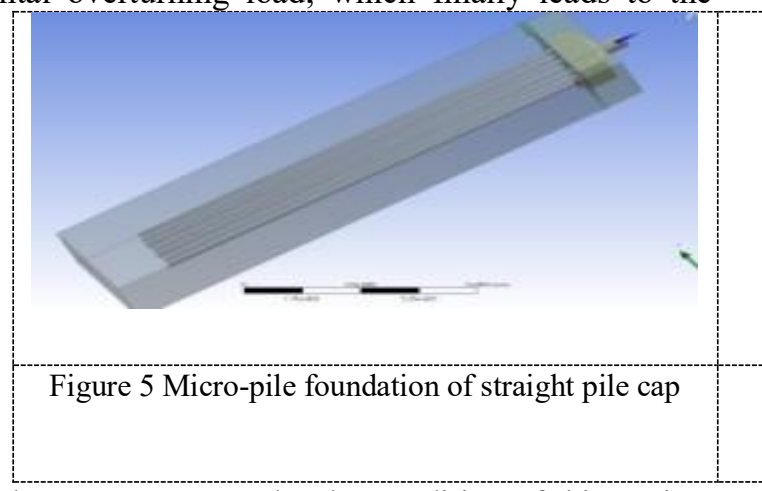

Each corner tower under the condition of this project 2 e 3 - SJC1 pulling force on the basis of the two, on the basis of comparing two kinds of foundation under the pulling force of mechanical performance, based on as shown in Figure7 and Figure8 group pile foundation stress and strain distribution cloud image contrast can be seen, nine straight pile and inclined pile cap miniature pile foundation stress performance is better than nine straight pile caps miniature pile foundation. The mechanical performance of the miniature inclined pile difficulty of theoretical design and calculation. The miniature pile mainly includes the design and calculation of the bearing capacity of the uplift, the design and calculation of the bearing capacity of the compression, and the analysis of the horizontal bearing capacity. ANSYS WORKBENCH is used to establish the nine-straight pile cap micro-pile foundation and the nine-straight pile-inclined pile cap micro-pile foundation respectively (as shown in Figure 5and 6), to explore its mechanical performance and optimize it.

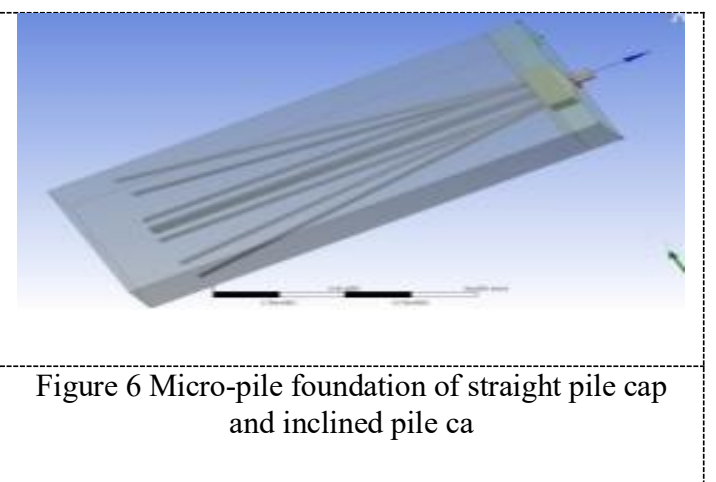

can be improved by $20 \%-30 \%$. In addition, as can be seen from the stress distribution cloud diagram of the micro-pile foundation of the nine caps of straight pile and inclined pile, due to the use of inclined pile, the part of the whole pile group with a large stress is mainly concentrated on the upper part of the whole pile length direction. Therefore, when carrying out the secondary grouting, pipe can be placed in the key part for local strengthening measures.

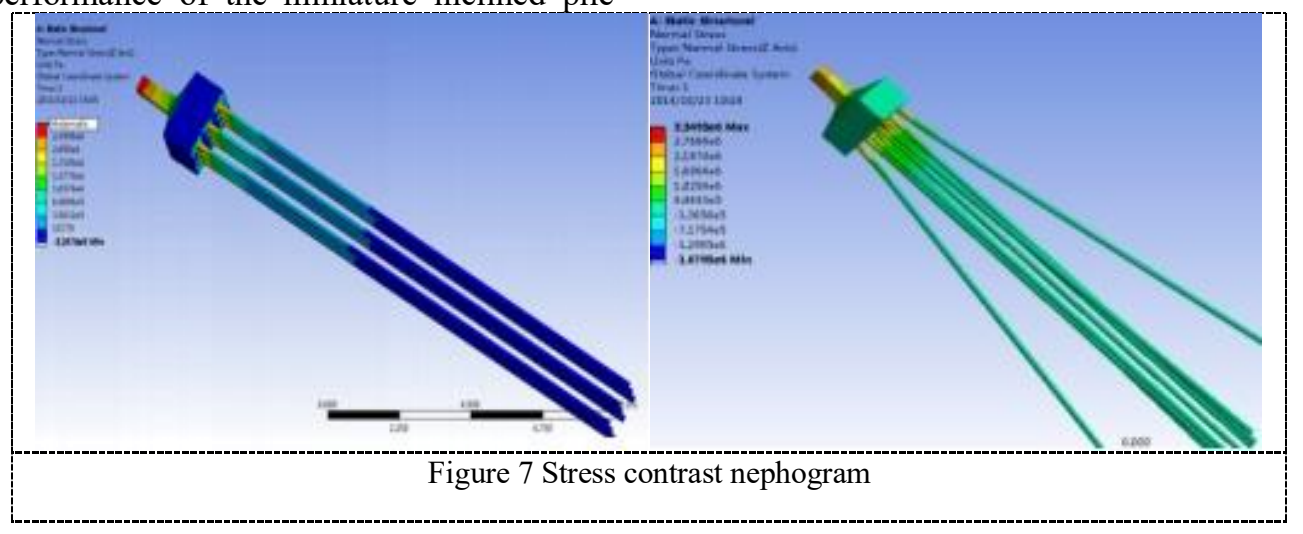




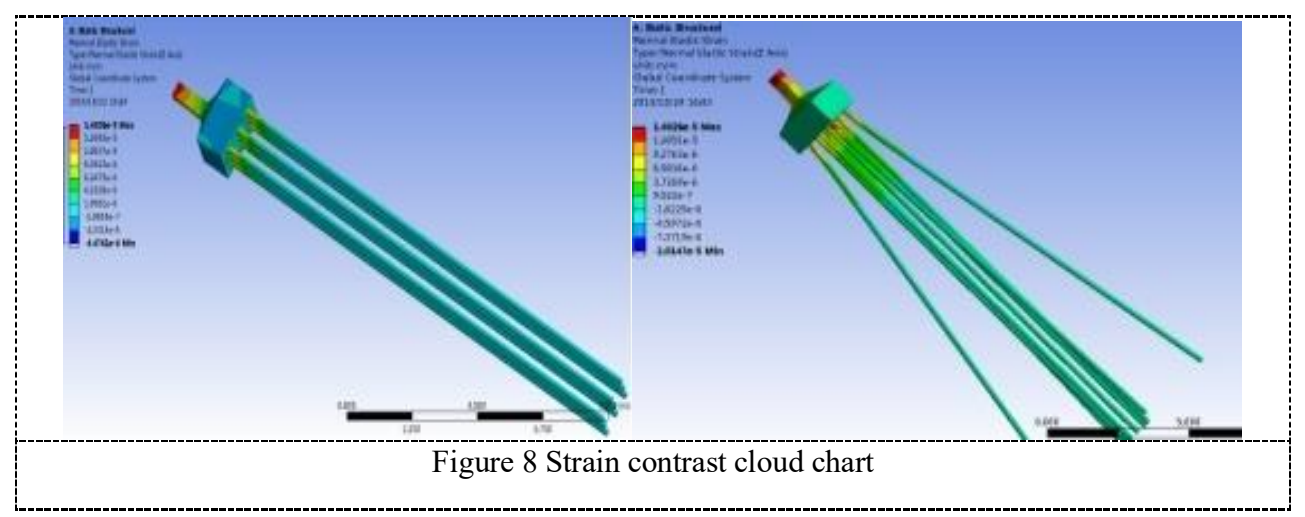

\section{Conclusions and recommendations}

This paper introduces the type of miniature pile foundation, its construction and economy, and draws the following conclusions and suggestions by using ANSYS WORKBENCH:

(1) When the construction conditions are allowed, the economic index of the foundation of four pile caps with miniature piles is lower than that of the foundation of bored piles.

(2) Miniature pile construction machinery is more miniaturized, so as to reduce the cost of green compensation and construction platform construction.

(3) ANSYS WORKBENCH finite element model was established to conduct stress simulation on the feasibility of the four pile cap foundation in the tower position of this project. The experimental results proved that it was feasible to use the four pile cap mini-pile foundation if the construction technology allowed.

(4) A miniature pile model with nine caps of straight pile and nine caps of inclined pile was established. According to the comparison of forces, the mechanical performance of the foundation of the miniature pile model with nine caps of straight pile was obviously better than that of the miniature pile foundation with nine caps. The mechanical performance of the miniature inclined pile can be improved by $20 \%-30 \%$.

\section{References}

1. Experimental study on micro-hydrostatic steel tube pile grouting technology [J]. Zong zhongling, wu jiangchuan, Li qingsong, Zhang kui. Construction technology. 2018(03)

2. Li zhan, teng yanjing, Li qinrui, Duan qiwei, Li dezhi, Tao deming. Journal of civil engineering. 2015(S2)

3. Xiang bo, ma jianlin, He yunyong, Zhou lirong. Journal of geotechnical engineering. 2013(11)

4. Analysis on the ultimate anti-slip force of steel tube miniature pile $[\mathrm{J}]$. Ma quanzhou. Journal of railway engineering. 2012(09) 